Chapter 7

\title{
Hematopoiesis Dysfunction Associated with Abnormal Thyroid Hormones Production
}

\author{
Miłosz P. Kawa and Bogusław Machaliński \\ Additional information is available at the end of the chapter \\ http://dx.doi.org/10.5772/58531
}

\section{Introduction}

Thyroid hormones (THs), the only known iodine-containing compounds with biological activity, are important for normal development of human organism, affecting the function of virtually all systems [1]. The thyroid gland releases primarily thyroxine (T4), which is converted in peripheral tissues by the enzyme thyroxine 5 '-deiodinase to the active TH form, 3,3', 5-triiodo-L-thyronine (T3) [1]. Thyroid hormone action is predominantly the result of T3 binding to high-affinity nuclear TH receptors (TRs) that have different tissue distribution and metabolic targets. TRs subsequently interact with specific DNA sequences, called thyroid hormone response elements (TREs), located in the regulatory region of different target genes [2]. Although both T3 and T4 enter the cells, only T3 is the ligand for TRs. When T3 binds to TR, specific co-factors are recruited and transmit signals to basal transcriptional machinery, thus inducing conformational changes of the chromatin, and making the selected genes accessible to the transcription process [3]. Accordingly, the transcription of the target genes is regulated by T3 and, in this way triiodothyronine exerts its biological effects through the chosen products of the transcription process. There are two thyroid hormone receptor genes, $T R \alpha$ and $T R \beta$, located in humans on chromosomes 17 and 3, respectively. Although various TR isoforms have been reported, these isoforms can be categorized into TR $\alpha 1$, TR $\alpha 2$, TR $\beta 1$, which are widely distributed in the body, and a form with more limited expression, TR $\beta 2$ [4]. TR $\alpha 1$ and TR $\beta 1$ are the major products of $T R \alpha$ and TR $\beta$ genes, respectively. Alternative splicing of the 3'-most exon of TR $\alpha 1$ results in the generation of TR $\alpha 2$. Since the discovery of these TR isoforms, many studies have attempted to demonstrate their relative contribution to mediate thyroid hormone action in various tissues. However, a number of tissues that are well known targets of THs, is so far limited, and include the pituitary, bones, liver, skeletal and cardiac muscle, fat tissue and developing brain [1]. In addition to the variable expression of 
TRs in different tissues, the role of TH can vary in particular tissues. Likewise, the numerous effects by a single hormone on so many distinct tissues is surprising and underscores the vital role of thyroid hormones in cellular function. Therefore, the interpretation of studies on action of biological TH/TRs axis is dependent on understanding the complex nature of thyroid hormone action. It was found that TRs are a multi-functional proteins: they act as transcriptional repressors in the absence of ligand and as transcriptional activators in the presence of $\mathrm{T} 3$ [5]. Of note, there are reports that TR $\alpha 2$ reveals an inhibitory action against other active TRs [6]. Importantly, the majority of thyroid hormone actions are thought to be mediated by nuclear receptors, although a wide range of nongenomic effects of $\mathrm{TH}$ at the cellular level have been recognized in the last decade [7]. Cellular uptake of iodothyronines and the nuclear TRs are not implicated in the nongenomic actions of thyroid hormones. These specific TH activities have been described to be present in the cell membrane, various organelles, the cytoskeleton, and in cytoplasm. Plasma membrane-initiated actions of $\mathrm{TH}$ begin at $\alpha \mathrm{v} \beta 3$ receptor for integrin, which activates ERK1/2-dependant cascade of kinases and culminate in local membrane processes, like a modulation of ion transport systems or in complex intracellular events, such as cell proliferation [8].

The objective of this chapter is to provide a current overview of the impact of hyperthyroidism on physiological hematopoiesis in humans and experimental animals. The molecular mechanisms involved in thyroid-dependent regulation of hematopoietic cell growth and development, with insight on the effects of hyperthyroidism on hematopoietic stem cell proliferation, apoptosis and cell cycle have been described. Moreover, the potential direct role of thyroid hormones in regulating the development of main hematopoietic lineages, erythropoiesis and leukopoiesis, are discussed. Finally, a summary on hyperthyroidism and its correlation with thrombocytopoiesis and platelet counts in circulating blood is also given.

\section{Hyperthyroidism and hematopoiesis}

Thyroid hormones significantly affect the cell cycle, proliferation, apoptosis as well as differentiation and metabolism in different types of human cells throughout the entire life [9]. THs also play an important role in specific tissues during their growth and development. THs have been known to be important regulators of bone development and metabolism [10-12]. In this notion, thyroid hormones may also regulate a wide array of hematological parameters of peripheral blood due to their potential influence on cell functions of hematopoietic system. The association of thyroid disorders and abnormalities in hematological parameters is well known, however, evidence for a role of THs/TRs in hematopoiesis is unclear so far and mostly indirect. In 1881, Charcot showed for the first time that Graves' disease is associated with anemia. Two years later, Kocher observed a decreased number of red blood cells (RBCs) in the peripheral blood (PB) of patients after thyroidectomy. Likewise, direct and indirect effects of excessive or insufficient thyroid hormones on hematopoietic cell maturation and function, on the synthesis and action of hematogenous humoral factors, and on changes in established blood composition may play a role in the pathogenesis of abnormal functions of hematopoietic system that accompany different thyroid diseases. Moreover, various abnormalities in 
hematological status that occur in patients with thyroid diseases may range from subclinical laboratory abnormalities to clinically significant disorders that might strongly complicate the clinical course of particular thyroid disease. Indeed, erythrocytosis is fairly common in the course of hyperthyroidism [13-14], and importantly, all parameters involved in erythropoiesis return to normal, when an euthyroid state is obtained [15]. However, also anemia is present in 10 to 25 percent of these patients. With regard to white blood cells, elevated, normal, but also depressed, total leukocyte counts have been reported in hyperthyroid patients. Observing the specific types of leukocytes in circulating blood, only the slight decrease in the number of neutrophils and relative increase in the number of eosinophils and mononuclear cells have been recorded in hyperthyroid patients. Nevertheless, the hyperplasia of all myeloid lineages in the bone marrow has been described in several cases of hyperthyroidism [16]. Interestingly, treatment with thyroid hormones has been suggested to improve reconstitution of the immune system after hematopoietic stem cell transplantation [17]. Besides, the clinical relationship between thyroid diseases and the hemostatic system was first defined in 1913 by Kaliebe and coworkers [18]. At that time authors have reported an episode of central vein thrombosis in a thyrotoxic patient. Different overt thyroid dysfunctions may cause thrombosis or hemorrhage by affecting primary and secondary physiologic hemostasis as this system requires careful regulation, also hormonal, in order to work properly [19].

Altogether, according to recent knowledge, the relationship between thyroid diseases and hematopoiesis is more complex than assumed and there are several molecular and patientbased studies on this subject in the scientific literature. Nevertheless, appropriate and adequate studies of high quality are lacking. In most of the reported studies, there are important methodological limitations, such as lack of control groups, small number of cases, and heterogeneity in etiology of the diseases, the severity of thyroid dysfunction and the usage of different laboratory methods. We review here some of the major advances in this area by initially focusing on what is known about molecular mechanisms of TH action on hematopoietic cells, with the particular insight into hematopoietic stem and progenitor cells, and discuss the implications of TH functioning in specific hematopoietic lineages. Although there is a great body of evidence that TH affect early hematopoietic cells in the indirect manner, the recent studies of our group suggested that THs may play a direct role in the regulation of the growth and apoptosis of human early hematopoietic cells [20-21].

\subsection{Thyroid hormone receptor expression in hematopoietic stem/progenitor cells}

In order to prove that thyroid hormones can directly influence hematopoiesis it is necessary to investigate in the first line the presence of the thyroid hormone receptor in hematopoietic stem/progenitor cells (HSPC). The expression of different TRs has been documented in mature cells of mouse bone marrow (BM), particularly in stromal cells [22], as well as in rat BM cells [23]. Besides, expression of mRNA for TR $\alpha 1$ receptor was reported in mononuclear cells isolated from human peripheral blood [17]. Recently, our group demonstrated for the first time that $\mathrm{TH}$ receptors (TR $\alpha 1$ and TR $\beta 1$ ) are expressed at mRNA and protein level in human $\mathrm{CD} 34^{+} \mathrm{HSPC}$ that were derived from different sources such as bone marrow and peripheral blood [20]. Importantly, we also analyzed TR $\alpha 1$ and TR $\beta 1$ expression in HSPC circulating in 
human umbilical cord blood and we found that TR $\alpha 1$ was expressed in both mRNA and protein form, however, TR $\beta 1$ gene had only the expression at the mRNA and not at the protein level [20]. The presence of different TRs in human early CD34 ${ }^{+}$hematopoietic cells is summarized in Figure 1.

A)



B)

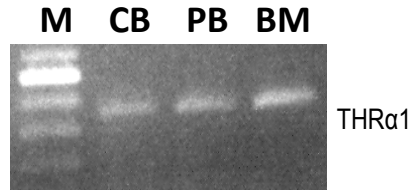

C) $M \quad$ CB PB BM

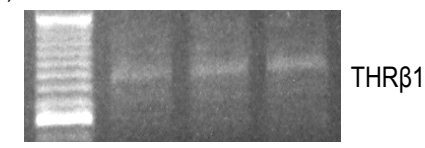

D) $\quad$ BM $\quad$ CB $\quad$ PB

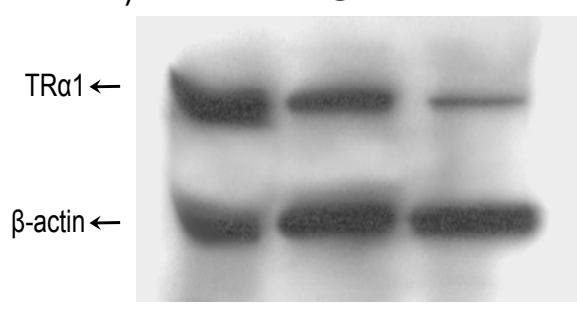

E) BM

CB PB

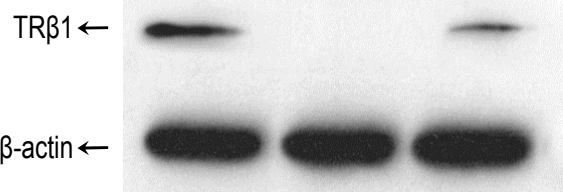

Figure 1. Analysis of TRa1 and TR $\beta 1$ expression at transcriptomic and translational level in human $\mathrm{CD}_{3} 4^{+}$-enriched hematopoietic stem/progenitor cells. Left panel: expression of mRNA for $\beta$-actin (A), TRa1 (B) and TR 1 (C) in $\mathrm{CD} 34^{\text {thuman }}$ cells obtained from cord blood (CB), peripheral blood (PB), and bone marrow (BM). Right panel: expression of protein for TRa1 (D) and TR 1 (E) in CD34+human cells obtained from bone marrow (BM), cord blood (CB), and peripheral blood (PB). M-molecular marker of DNA weight. Modified from: [20].

Interestingly, we recently observed that the abnormal concentrations of thyroid hormones may influence the rate of expression of different TRs in hematopoietic cells. To investigate the molecular changes underlying the enhanced influence of THs on circulatory HSPCs, we analyzed the expression of TR $\alpha$-1 gene in CD34+-enriched HSPCs isolated from the PB of healthy subjects. When HSPC population was subjected for period of 72 hours to triiodothyronine at concentration ten times higher than normal physiological concentration (equal to 3.7 $\mathrm{pg} / \mathrm{mL}$ ), which quite resemble the natural conditions of hyperthyroid state in human patients, the expression of mRNA for $T R \alpha-1$ gene was down-regulated in the majority of analyzed blood samples as shown in Figure 2 [21].

Furthermore, our group found that in patients with hyperthyroidism the levels of mRNA for TR $\alpha$-1 expressed by CD34+-enriched HSPCs were significantly decreased by around $37 \%$ compared to HSPCs isolated from control healthy subjects (254.9 vs. 398.3, respectively; amount of the transcript given in arbitrary units; $\mathrm{P}<0.01$ ) as determined by real-time PCR [21]. Additionally, the results indicating the direct influence of THs on TR expression were qualitatively corroborated by the immunocytofluorescence analysis of TR $\alpha-1$ protein expression in PB-derived CD34+-enriched HSPCs obtained from patients with overt thyroid dys- 


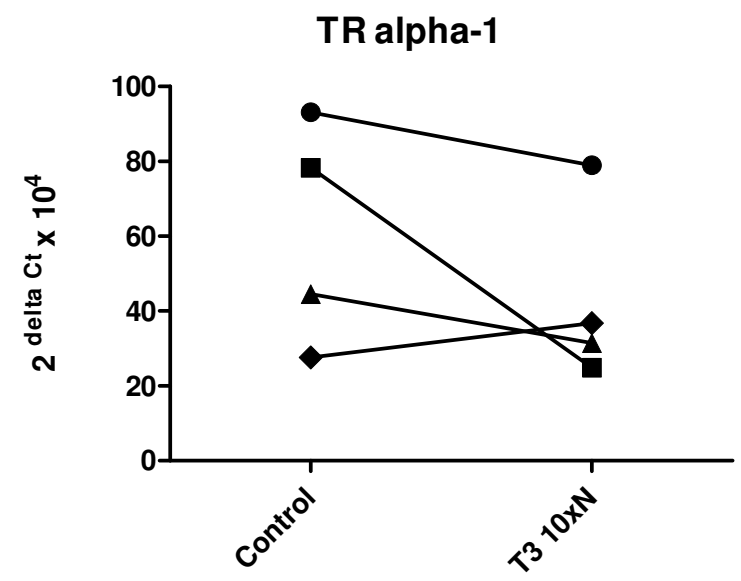

Figure 2. Expression of mRNA for TRa-1 in human CD34+-enriched hematopoietic stem/progenitor cells incubated with increased concentration of T3. Gene expression of TRa- 1 was assessed by real-time RT-PCR in CD34+cells collected from healthy donors and incubated through 72 hours with serum saline (Control) or with ten times higher than normal concentration of T3 (T3 $10 \times \mathrm{N})$. The amount of the transcript is expressed in the arbitrary units. Each line represents TRa-1 expression in cells collected from particular subject [21].

function. Here, the fluorescence signal of cells from hyperthyroid patients was much weaker than signal of equal cell population from healthy donors. Interestingly, HSPCs from hypothyroid patients presented the most intense fluorescence signal in this analysis performed in the established and fixed conditions. The summary of data obtained from in vitro investigation using immunofluorescence to detect TR $\alpha-1$ protein expression is presented in Figure 3.

Altogether, the above findings may indicate that $\mathrm{T} 3$ at high concentration might reduce the expression of TR $\alpha-1$ in circulating CD34+-enriched HSPCs due to active trafficking of protein receptors and possible intense biodegradation after terminating its role in cell signaling. The process of shuttling of TR between cytoplasm and nucleus directly after TH stimulation was also observed [24]. Alternatively, a biologically controlled ligand-negative loop that form homeostatic mechanism regulating cell activity may prevent the possibility that more ligand binding to specific receptors could actively induce different cellular processes in TR-expressing cells. Therefore, the active reduction of mRNA expression or inhibition of TR protein production would result in prevention against cellular hyperactivity in the hyperthyroid state of the organism, also in the hematopoietic cells of patients with hyperthyroidism. Similar data were obtained by Meier-Heusler et al., who documented a decreased expression of TR $\beta-1$ in mononuclear cells of peripheral blood from hyperthyroid patients and they noted that the levels of mRNA for TR $\beta-1$ were about $40 \%$ lower than in euthyroid subjects [25]. Correspondingly, previous observations by Rao et al. suggested a significant trend towards a downregulation of $T R \alpha-1$ mRNA levels in the other tissues under the hyperthyroid state, such as rat testes [26]. These data suggest that specific cellular TR expression is sensitive to the pathological conditions related to hyperthyroidism developed in the affected organism. 


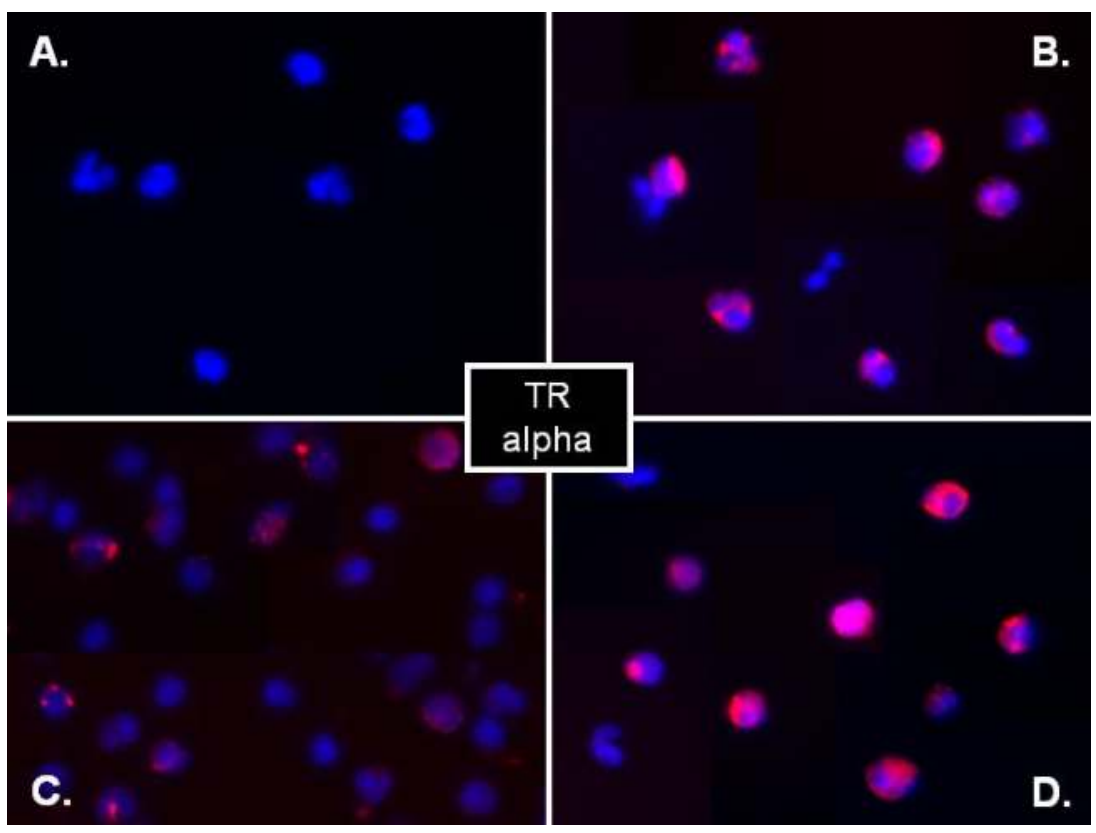

Figure 3. Immunocytofluorescence of TRa-1 protein in human CD34+-enriched hematopoietic stem/progenitor cells. CD34+cells from healthy donors (B), hyperthyroid patients (C), and hypothyroid patients (D) were stained with anti-TRa-1 antibody (pseudo-colored red). Cell nuclei (A-D) are visualized with DAPI (pseudo-colored blue) [21].

\subsection{Hyperthyroidism and lineage-specific clonogenic growth of hematopoietic cells}

The hematopoietic system is very sensitive to thyroid hormones and hyperthyroidism may induce significant alterations in growth of hematopoietic stem/progenitor cells, originally located in bone marrow as well as constantly circulating in peripheral blood, and thus significantly exposed to biologic activity of free THs. Unfortunately, our current knowledge concerning the influence of THs on clonogenicity of human HSPCs is very limited and mostly based on studies performed in animal models or human tissues cultured ex vivo. However, such studies, performed in part also by our group, expanded the understanding of the role of thyroid disorders in normal human hematopoiesis and could show a direct pathophysiological influence of $\mathrm{T} 3$ on this process.

\subsubsection{Erythropoiesis}

Erythropoiesis is the physiologic process in which red blood cells (RBCs) are produced. Hematopoietic development within the erythroid lineage requires a delicate balance between the opposing effects of proliferation-promoting factors that maintain the renewal capacity of immature erythroid progenitors and differentiation-inducing factors required for successful terminal maturation of erythroid progenitors into mature erythrocytes [27]. In vivo, both the renewal and maturation of human erythroid progenitors proceed in the bone marrow in 
parallel. Although thyroid hormones are required for normal development and differentiation of many cell types, little is known about their role in physiologic erythropoiesis, especially in humans [4]. On one side, hyperthyroidism induced in experimental laboratory animals or in humans, generates increased RBC number and total RBC mass through stimulation of erythropoiesis [28-29], however, it has been postulated that this effect would be indirect and involves modulating function of biologically active substances important for erythropoiesis, such as kidney-derived erythropoietin (EPO) or other hematogenous humoral factors, which production by non-erythroid cells is also increased in hyperthyroid state [30-31]. Besides, there are evidences that THs may increase the concentration of 2,3-diphosphoglycerate in erythrocytes, which serves to enhance the delivery of oxygen to tissues, and thus affects steady-state levels of circulating EPO [32-33]. Interestingly, in vitro studies confirmed that both T4 and T3 stimulate EPO synthesis in the human liver cell line HepG2 and this stimulating effect could persist for 24 hours after the removal of THs from the cell culture [34]. However, in the established model of HSPCs cultures in vitro with standard amount of EPO performed for analysis of differential clonogenic growth of hematopoietic cells, we observed that proliferative potential of burst-forming units of erythrocytes (BFU-E) was increased only in the samples collected from the patients with hyperthyroidism and, in contrast, it was decreased in case of samples collected from the hypothyroid subjects [21]. Therefore, it seems that THs can induce signal transduction pathways implicated in proliferation of hematopoietic progenitors for erythroid lineage other than EPO-dependent mechanisms. Data from in the available literature corroborate our discovery indicating the direct role of THs in normal erythroid differentiation of human and animal origin [35-38]. For example, daily administration of thyroxine into mice stimulated the increase of indices significant for RBC production, such as packed red blood cell volume, total circulating RBC count and mass, and reticulocyte count [39]. Likewise, Malgor et al. have studied the TH role on modulation of erythropoiesis using the in vitro cultures of cells collected from bone marrow of normal rats in the absence of EPO [37]. They found that T3 produced a direct and significant stimulation of clonogenic growth of late colony-forming erythroid units (CFU-E) and a moderate increase of early erythroid burstforming units (BFU-E) indicating an enhanced proliferative activity of committed erythroid progenitors in response to this hormone. In contrast, the addition of T3 to in vitro cultures of avian BM cells activates the TR $\alpha$ receptor in avian erythroblasts, blocks their self-renewal, and induces synchronous, terminal differentiation of erythroid lineage from hematopoietic progenitor cells [40]. Notwithstanding, Kendrick et al. recently verified the essential function of TR $\alpha$ in regulating erythropoiesis in mammals by characterizing the phenotype of TR $\alpha-/-$ mice deficient for TR $\alpha$. These transgenic mice had significantly reduced numbers of erythroid progenitor cells in the fetal liver, decreased hematocrit in adult organism, and a diminished erythroid stress response to hemolytic anemia [41]. Similar results of direct TH influence on erythroid lineage growth were taken from observations of human erythropoiesis developed in vitro in established conditions. In pioneer studies of human BM-derived cells and THs action Golde et al. showed that THs do not shift the requirement for EPO in the course of human erythropoiesis, but both substances have synergistic effects in increasing the number of erythroid colonies growing in vitro [35]. These data were corroborated by Leberbauer et al., who recently demonstrated that terminal erythroid maturation in course of development of 
human erythroblasts obtained from umbilical cord blood is significantly improved by supplementation of T3 to the defined culture medium [42]. Likewise, we performed a quantitative molecular analysis of hematopoietic stem/progenitor cell proliferation based on the expression levels of mRNA for the Cyclin D1 and PCNA genes, which are concerned to be important for the cell cycle regulation. We found in our study, the nearly $100 \%$ increase in expression of mRNA for both analyzed genes in PB-derived CD34+-enriched HSPCs collected from subjects with hyperthyroidism (Figure 4), thus indicating that THs significantly stimulates up-regulation of genes involved in the induction of hematopoietic cell proliferation [21].

A

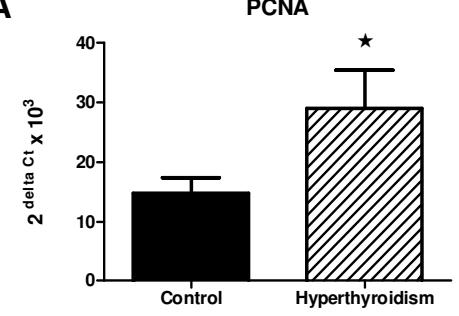

B

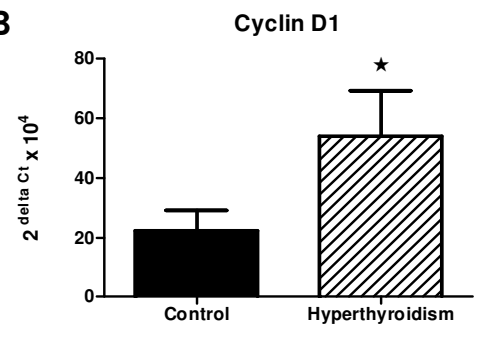

Figure 4. Expression of mRNA for PCNA and Cyclin D1 in human CD34+-enriched hematopoietic stem/progenitor cells collected from hyperthyroid patients. Gene expression of PCNA (panel A) and Cyclin D1 (panel B) was assessed by realtime RT-PCR in CD34+cells isolated from PB of patients with hyperthyroidism and healthy donors (Control). The mean amount of the selected gene transcript $( \pm S D)$ is expressed in the arbitrary units. $P<0.05$. [21]

These molecular data correlate strongly with increased potential of erythroid progenitor cell growth observed in our study performed on CD34+-enriched HSPCs from PB of patients with thyroid dysfunction using in vitro proliferation assays [21]. Erythroid BFU-E colonies cultivated from $\mathrm{CD} 34^{+}$cells that were collected from circulating blood of patients with hyperthyroidism exhibited in average a $40 \%$ increase of their clonogenic growth compared to the healthy control group $(\mathrm{P}<0.05)$. Importantly, in the group of patients with hyperthyroidism comprised of 25 persons of whom 52\% were patients with Graves' disease and $48 \%$ with toxic nodular goiter, we also observed a significant increase in the number of mature RBCs in the PB. Furthermore, RBCs from our cohort possessed increased mean corpuscular volume, but reduced mean corpuscular hemoglobin concentration and mean hemoglobin mass. These findings together might indicate that erythroid progenitors that are overproduced in BM of hyperthyroid patients under the abnormal T3 stimulation would generate mature RBCs circulating in excess in peripheral blood. However, cellular structure and composition of circulating RBCs was also affected. Of note, our study group presented the mild increase in free T3 concentration compared to healthy volunteers who served as control group $(2.71 \pm 1.14$ vs. $6.95 \pm 3.13 \mathrm{pg} / \mathrm{mL}$ of $\mathrm{T} 3$, respectively).

However, there is a few studies with contradictory results investigating the functional effect of thyroid abnormalities on the RBC counts in peripheral blood. Gianoukakis et al. have measured the RBCs in 87 hyperthyroid patients with Graves' disease and 19 healthy subjects. The average number of RBCs was found to be lower in the $36 \%$ of recruited hyperthyroid 
subjects compared to the healthy individuals. Nevertheless, in the group of selected patients with anemia, the mean EPO levels were significantly higher $(\mathrm{P}=0.004)$ than those of the nonanemic controls [43]. According to other authors, anemia is present in 10 to 25 percent of patients with hyperthyroidism [15, 44]. This finding may be the result of increased plasma volume, as reported effect of increased T3 concentration in humans [45] and animal model [39], but also the result of autoimmune processes leading to anemia in Graves' disease, such as pernicious anemia and autoimmune hemolytic anemia, which concurrently may develop [46]. In addition, decreased RBC survival and ineffective erythropoiesis in course of hyperthyroidism have been described [47-48]. Pancytopenia in the setting of hyperthyroidism has also been reported in the literature. Most cases of pancytopenia have been associated with Graves' disease and one case with toxic adenoma, and TH-related stem cell dysfunction has been suggested there as one possible mechanism among others [49-51]. Likewise, our group observed that heavily non-physiological concentrations of T3, such as ten times higher or fifty times higher than physiological concentration of free T3 significantly negatively influenced the in vitro growth of erythroid BFU-E colonies in proliferation assays derived from human CD34 ${ }^{+}$HSPCs circulating in peripheral blood. This effect was even more noticeable after prolonged exposure to increased non-physiological T3 amounts [20]. This may explain the abnormalities in RBC counts observed in some patients with hyperthyroidism, especially those with advanced and chronic disease. In contrast, the in vitro clonogenic potential of erythroid BFU-E progenitors was considerably increased in physiological concentration of free T3 as well as in mildly increased concentration of T3 such as five times higher than normal physiological one [21]. The mean numbers of the colonies of erythroid BFU-E obtained in our study are presented in Table 1.

\begin{tabular}{cccccc}
\hline Free T3 concentration & & $\mathbf{N}$ & $\mathbf{5 x N}$ & $\mathbf{1 0 x \mathbf { N }}$ & $\mathbf{5 0 \times \mathbf { N }}$ \\
\hline Parameter & Incubation & $\%$ & $\mathbf{\%}$ & $\%$ & $\%$ \\
\hline Growth of BFU-E from BM & 24 hours & 100.00 & $103.5 \pm 30.7$ & $85.6 \pm 29.1$ & $70.6 \pm 54.4$ \\
\hline Growth of BFU-E from PB & 72 hours & 100.00 & $108.9 \pm 43.9$ & $88.25 \pm 46,9$ & $49.2 \pm 18.2^{*}$ \\
\hline Growth of BFU-E from CB & 24 hours & 100.00 & $114.0 \pm 42.9^{*}$ & $104.0 \pm 20.2$ & $65.0 \pm 12.2^{*}$ \\
\hline & 72 hours & 100.00 & $101.0 \pm 50.3$ & $63.0 \pm 36.2$ & $59.0 \pm 13.9^{*}$ \\
\hline
\end{tabular}

Table 1. Influence of T3 on clonogenicity of human BFU-E after 24-and 72-hour incubation with increasing free T3 concentrations. Cells $(n=5)$ incubated with: $\mathrm{N}=$ physiological dose of T3 $(3.7 \mathrm{pg} / \mathrm{mL}) ; 5 \times \mathrm{N}=$ five times higher than $\mathrm{N}$; $10 \times \mathrm{N}=10$ times higher than $\mathrm{N} ; 50 \times \mathrm{N}=50$ times higher than $\mathrm{N}$. Results are expressed as mean percentage ( \pm SD) of the control value obtained with established physiological dose of T3 taken as $100 \%$. P $<0.05$ [20].

\subsubsection{Leukopoiesis}

Leukopoiesis is the process of white blood cells (WBCs) formation from hematopoietic stem cells placed in hematopoietic organs. Leukocytes are a heterogeneous group of blood cells that 
all have nuclei and include granulocytes (i.e. neutrophils, eosinophils, and basophils), monocytes, lymphocytes T and B, as well as natural killer cells. Leukopoiesis is stimulated by different cytokines, interleukins, colony-stimulating factors and several hormones. The body of information on the relationship between thyroid hormones and WBC biology is relatively large and describes contribution of thyroid hormones to the modulation of physiological leukocyte activities such as chemotaxis, phagocytosis, respiratory burst, cytolytic activity, and cytokine synthesis in monocytes/macrophages and different types of lymphocytes. Nevertheless, the data available are frequently difficult to interpret or even contradictory, when related to growth and proliferation of specific leukocyte types. This situation is even more complicated by the fact, that WBCs are able to produce several hormones or hormone-like molecules [52], and the expression of thyroid hormones has been reported in several WBCs, like monocytes, granulocytes, natural killer cells, mast cells, and lymphocytes [53-54]. It is also known that T3 is able to modulate functions of immune-related cells either via nuclear receptors that are responsible for genomic $\mathrm{TH}$ activities, and by interactions with other membrane receptors for THs that conduct non-genomic actions of THs [1].

In general, it was found that physiological concentrations of thyroid hormones positively correlates with the immune cell parameters/functions, such as cell counts and induction of different physiological activities of particular WBC populations. Few reports analyzing the in vitro actions of THs showed modifications in lymphocyte reactivity [55-56]. However, the direction and magnitude of these alterations might depend on the type and concentration of the $\mathrm{TH}$ encountered by the responding cells, and the species source of lymphoid cells. For example, it was found that THs within the normal physiological range may increase a mitogeninduced normal $\mathrm{T}$ lymphocytes proliferation through both the genomic and non-genomic mechanisms [57]. Furthermore, Hodkinson et al. measured plasma thyroid hormone levels in 93 late-middle aged healthy euthyroid subjects, and calculated the mean T3/T4 ratio, and next used these numbers to distinguish between low-and high-thyroid hormones concentration, but still within the normal physiological range, and found a significant positive association between thyroid hormones concentration and natural killer T-cell percentage and monocytes count [58]. In addition, in the same study there was also a significant inverse association of THs levels with the expression of early lymphocyte apoptosis markers [58]. Recently, it has been proposed that thyroid hormones are significant for leukopoesis as highly involved in maintaining immune system homeostasis in response to environmental changes or stressmediated immunosuppression [59]. Further evidences from studies on mammals indicate that thyroid hormones have important immunomodulatory effects. Likewise, T3 enhances phytohaemagglutinin stimulation of human lymphocytes [60]. Concurrently, El-Shaikh et al. have shown that the daily subcutaneous supplementation of T4 in BALB/c mice for one month induces an increase in the total number of peripheral blood leukocytes, as well as augments cellularity of thymus and spleen parenchyma, and peripheral lymph nodes [61]. In general, developed hyperthyroid state induces the increase in the immune system functions related to the antibody production, immune cell migration, and reactive oxygen species production, whereas it decreases the proinflammatory markers expression, the antioxidant enzymes production, and their cellular activity [62]. Notwithstanding, in other in vivo study performed 
in rats, the induction of hyperthyroidism did not affect the ratio of helper to suppressor $\mathrm{T}$ lymphocytes in the examined immune system [63].

Due to the contrasting results revealed in some previous reports, it is quite difficult to establish a clear correlation between hyperthyroidism and immune functions [62]. These discrepancies may be largely attributed to differences in the duration of disease, age and gender of animal and human subjects and hyperthyroidism origin, or even the treatment mode given to the patients with thyroid disease. Especially, previous studies on human different WBC population counts and function during hypo-and hyperthyroid states produced conflicting results. Indeed, a significant decrease in the lymphocyte and increase in monocyte count were observed in patients with autoimmune thyroiditis [64], however, similar changes in the number of lymphocytes were also observed in autoimmune hyperthyroidism [65]. Thus, it is supposed that the changes in number of lymphocytes in different thyroid autoimmune dysfunctions are due to the autoimmune process alone, and not due to the direct influence of thyroid hormones specifically on lymphopoiesis. Possibly, the elevated number of lymphocytes in autoimmune-related thyroid disorders may demonstrate a nonspecific activation of the immune system as it is found in some other autoimmune-derived diseases in humans [66-67]. Our own results performed in the selected group of patients with hyperthyroidism showed a tendency to decrease the general WBC number in circulating peripheral blood. Thus, we were mostly interested in biology of hematopoietic stem and progenitor cells of myelomonocytic lineage from these subjects, as appeared that this lineage may be clearly independent from autoimmune responses developed in this patient group and might be affected by abnormal THs concentration. It appears from the available literature that the relationship between thyroid hormones and myelopoiesis has been studied mainly based on hematopoietic cells collected from peripheral blood of healthy subjects. Unfortunately, the current knowledge concerning the influence of THs on clonogenicity of progenitors for granulocytes and monocytes that grown as colony forming units of granulocytes and monocytes (CFU-GM) is very limited. There are only few reports on the influence of physiological T3 concentration on clonogenic potential of human CFU-GM cells. For example, Notario et al. observed that both thyroid hormones, T3 and T4, are able to enhance the colony growth of CFU-GM obtained from normal PB, and interestingly, the response is more evident for T4 than T3 [68]. Moreover, the second report of this group revealed that there is a synergistic effect of THs and different hematopoietic growth factors, like G-CSF, GM-CSF, and IL-3, which are substantial for proliferation of progenitors for myelomonocytic lineage [69]. In contrast, Ponassi et al. reported an abnormal granulopoiesis in nearly 50 percent of patients with untreated Graves' disease, based on the pharmacological test with mobilization of the marrow granulocyte reserve by hydrocortisone [70]. However, no data on clonogenic potential of hematopoietic progenitor cells in the presence of different nonphysiological concentrations of thyroid hormones were reported in either of these studies. Therefore, our group recently analyzed the in vitro growth of myeloid CFU-GM colonies derived from human CD34 ${ }^{+} \mathrm{HSPC}$ in proliferation assays with growing non-physiological concentrations of free T3. We observed that clonogenic potential of CFU-GM colonies from CD34 ${ }^{+} \mathrm{HSPCs}$ of healthy subjects was considerably increased in concentration of T3 only moderately higher (5x) than the physiological T3 concentration [20]. In contrast, the much higher non-physiological concentrations of T3, such as ten times higher 
or fifty times higher than physiological T3 concentration significantly negatively influenced the growth of myeloid CFU-GM colonies derived from CD34 ${ }^{+} \mathrm{HSPC}$ collected from peripheral blood as well as umbilical cord blood. This effect was even more significant in case of myeloid CFU-GM colonies derived from CD34+HSPCs harvested from the bone marrow of healthy donors [20]. In addition, we noticed an enhanced negative effects of non-physiological concentrations of T3 in the case of prolonged in vitro exposure to the triiodothyronine (72hour-period). The mean numbers of the colonies of myeloid CFU-GM obtained in our study are presented in Table 2.

\begin{tabular}{cccccc}
\hline Free T3 concentration & & $\mathbf{N}$ & $\mathbf{5 x N}$ & $\mathbf{1 0 x N}$ & $\mathbf{5 0 x \mathbf { N }}$ \\
\hline Parameter & Incubation & $\%$ & $\mathbf{\%}$ & $\mathbf{\%}$ & $\mathbf{\%}$ \\
\hline Growth of CFU-GM from BM & 24 hours & 100.00 & $77.8 \pm 19.6^{*}$ & $72.6 \pm 18.7^{*}$ & $50.1 \pm 8.7$ \\
\hline Growth of CFU-GM from PB & 72 hours & 100.00 & $91.0 \pm 36.7$ & $97.2 \pm 47,7$ & $49.2 \pm 18.2^{*}$ \\
\hline & 24 hours & 100.00 & $154.0 \pm 18.7^{*}$ & $101.0 \pm 14.5$ & $90.0 \pm 35.8^{*}$ \\
\hline Growth of CFU-GM from CB & 72 hours & 100.00 & $292.0 \pm 26.6^{*}$ & $205.0 \pm 17.5^{*}$ & $141.0 \pm 29.4^{*}$ \\
\hline & 24 hours & 100.00 & $106.3 \pm 28.4$ & $92.7 \pm 11.6$ & $93.8 \pm 35.7$ \\
\hline
\end{tabular}

Table 2. Influence of T3 on clonogenicity of human CFU-GM after 24-and 72-hour incubation with increasing free T3 concentrations. Cells $(n=5)$ incubated with: $\mathrm{N}=$ physiological dose of T3 $(3.7 \mathrm{pg} / \mathrm{mL}) ; 5 \times \mathrm{N}=$ five times higher than $\mathrm{N}$; $10 \times \mathrm{N}=10$ times higher than $\mathrm{N} ; 50 \times \mathrm{N}=50$ times higher than $\mathrm{N}$. Results are expressed as mean percentage ( \pm SD) of the control value obtained with established physiological dose of T3 taken as $100 \%$. P $<0.05$ [20].

The abovementioned results clearly correlated with clonogenic potential of CD $34^{+}$-enriched HSPCs collected from subjects with diagnosed thyroid dysfunction [21]. In our clinical study, we examined the clonogenicity of $\mathrm{CD} 34^{+} \mathrm{HSPC}$ harvested from $\mathrm{PB}$ of hyperthyroid patients using the in vitro proliferation assays, and we found that the number of CD34+-expanded CFUGM colonies was significantly lower in this group than that observed in healthy euthyroid subjects (66 vs. $100 \%$ respectively; $\mathrm{P}<0.05$ ).

One of the possible explanations for the diminished clonogenic growth of CFU-GM derived from hyperthyroid patients might be the TH-dependent cell death induced in circulating and BM residual HSPCs. Cell death has been broadly classified into two categories, necrosis and apoptosis. Of note, there is ongoing debate as to the mutually exclusive nature of these two categories of cell death, and it seems possible that there are many intermediate subcategories. However, necrotic cell death is always a pathological event occurring in response to strong cell/tissue injury or environmental insult. In contrast, apoptosis is an energy-requiring process that often involves altered expression of key cell proliferation and death-inducing genes. It is known that THs, like many other hormones acting through nuclear receptors, are important regulators of cellular proliferation and apoptosis [71-72]. At the cellular level, both T3 and T4 induce apoptosis in different cell types, like rat pituitary cell lines [73-74], rat cardiomyocytes [75], and human breast cancer cells [76], when exposed 
to THs in vitro or in vivo. It was observed that in HeLa cervix cancer cell line T3 induces caspase activity, which plays a key role in the execution of apoptosis [77]. In contrast, the physiological concentrations of both T3 and T4 inhibited apoptosis in rat brainderived endothelial cells in vitro through alterations in the mRNA levels of apoptosisrelated genes, such as $B C L-2$ and $B A D$ [78]. T4 was able to inhibit the resveratrol-induced apoptosis in glioma cells in vitro through nongenomic mechanisms, employing integrin receptor and ERK-mediated cascade [79]. Alike, previously mentioned Hodkinson et al. observed that under normal physiological conditions T3 reduced incidence of lymphocyte apoptosis in healthy older individuals [58]. Similarly, Barreiro Arcos et al. observed, that $\mathrm{TH}$ treatment augments the mitogen-induced proliferation of normal $\mathrm{T}$ lymphocytes [80]. Altogether, TH-mediated effects on cellular apoptosis depend on the type and developmental or pathophysiological state of the selected cells and tissues. Importantly, there are many compounds and circumstances that can induce cell apoptosis. It is known that a particular agent may produce apoptosis in a given cell or tissue, but may not in another, or in a given cell at one period of the cell cycle, but not at another. Whether a cell responds to such an agent by induction of programmed cell death, it must therefore depend on the specific array of interactive molecular regulatory systems active in that cell at that time [81]. In case of cells related to hematopoietic system, the pro-apoptotic actions of THs were defined in normal and tumor-derived lymphocytes. In this notion, Mihara et al. demonstrated that $\mathrm{T}$ lymphoma cells from the human Jurkat cell line, cultured in vitro for 2 weeks with addition of T3 and T4, showed their enhanced apoptosis [82]. This group also showed that $\mathrm{T}$ lymphocytes from healthy volunteers cultured with $\mathrm{T} 3$, but not T4, for five days exhibited an increase in the percent of spontaneous apoptosis, thus indicating that longterm exposure to T3 induces accelerated lymphocyte apoptosis in vitro [82]. Indeed, Mihara and coworkers found also significantly higher percentage of apoptotic T lymphocytes in vivo from patients with chronic Graves' disease than from healthy subjects [82]. Moreover, Gandrillon et al. determined that THs increased apoptosis rate in early erythrocytic progenitor cells [83], and similar effect was observed by Hara et al. in hematopoietic HL-60 cells of promyeloleukemic lineage [84]. To put the light on the possible pathophysiological mechanisms of such decreased proliferative potential of CD34 HSPCs in high nonphysiological T3 concentrations reported by our group, we analyzed the process of apoptosis in HSPCs collected from different compartments of human hematopoietic system, such as bone marrow, peripheral blood or umbilical cord blood [20]. In our study, we performed the analysis of potential influence of T3 on the apoptosis induction in human $\mathrm{CD} 34^{+}$-enriched hematopoietic progenitor cells collected from the above hematopoietic cell sources of healthy subjects. Importantly, we analyzed the apoptosis in these cells employing three different molecular techniques as, according to specialists in this field, it is crucial for reliable detection of this phenomenon to confirm it by applying at least three distinct laboratory methods. For this reason, we used the flow cytometry-based detection of annexin$\mathrm{V}$, TUNEL technique detecting apoptosis-related abnormalities in cell genetic material, and finally, analysis of the expression level of pro-apoptotic Bax and both anti-apoptotic Bcl$x \mathrm{~L}$ and $\mathrm{Bcl}-2$ genes in the CD34 ${ }^{+} \mathrm{HSPCs}$ that were incubated with different non-physiological T3 concentrations $(5 \times N$; $10 \times N$; and $50 \times N$; where $\mathrm{N}$ is equal to established physiological 
T3 dose) for period of 24 or 72 hours. We found that after 24 hours all three used nonphysiological T3 concentrations markedly induced the apoptosis in analyzes hematopoietic progenitors, however the percentage of apoptotic CD34+HSPCs was significantly higher in samples collected from PB, CB and BM incubated with the highest dose [20]. Similar results were obtained for longer incubation through 72-hour-period. It was especially clearly noticeable in the detailed analysis of the apoptosis detected by TUNEL technique presented in Table 3. Correspondingly, when analyzing the mRNA expression for genes crucial for apoptosis in human early hematopoietic CD34 ${ }^{+}$cells after incubation with the fixed increasing T3 concentrations, we observed an augmented expression of pro-apoptotic $B A X$ gene and decreased expression of the anti-apoptotic genes: $B C L-x L$ and $B C L-2$ in these cells under exposure to T3 amount 50 times higher than the established physiological T3 concentration [20].

\begin{tabular}{cccccc}
\hline Free T3 concentration & & $\mathbf{N}$ & $\mathbf{5 x N}$ & $\mathbf{1 0 x \mathbf { N }}$ & $\mathbf{5 0 \times \mathbf { N }}$ \\
\hline Parameter & Time & $\%$ & $\%$ & $\%$ & $\%$ \\
\hline Apoptotic CD34+ HSPCs from BM & 24 hours & 100.00 & $144.5 \pm 39.4^{*}$ & $94.3 \pm 33.9$ & $87.4 \pm 47.6$ \\
\hline Apoptotic CD34+ HSPCs from PB & 72 hours & 100.00 & $179.0 \pm 25.5^{*}$ & $107.3 \pm 9,6$ & $119.1 \pm 11.0^{*}$ \\
\hline Apoptotic CD34+ HSPCs from CB & 24 hours & 100.00 & $115.1 \pm 20.5$ & $166.6 \pm 31.7^{*}$ & $98.8 \pm 20.4$ \\
\hline & 72 hours & 100.00 & $105.3 \pm 36.5$ & $122.5 \pm 17.8^{*}$ & $125.1 \pm 16.1^{*}$ \\
\hline
\end{tabular}

Table 3. Percentage of apoptotic cells detected with the established TUNEL method after 24-and 72-hour incubation of human $\mathrm{CD} 34^{+}$cells with increasing free T3 concentrations. Cells $(n=5)$ incubated with: $\mathrm{N}=$ physiological dose of T3 $(3.7 \mathrm{pg} / \mathrm{mL}$ ); $5 \times \mathrm{N}=$ five times higher than $\mathrm{N} ; 10 \times \mathrm{N}=10$ times higher than $\mathrm{N} ; 50 \times \mathrm{N}=50$ times higher than $\mathrm{N}$. Results are expressed as mean percentage $( \pm S D$ ) of the control value obtained with established physiological dose of T3 taken as $100 \% . P<0.05[20]$.

Our group was also interested to assess the influence of THs on apoptosis rate in PB-derived CD34+HSPCs circulating in peripheral blood of the patients with hyperthyroidism [21]. For this analysis, we used combined annexin- $\mathrm{V}$ and propidium iodate staining of hematopoietic cells detected by flow cytometry. This method especially provides the chance to assess apoptosis in two distinct stages, the early and late phase of apoptosis. In fact, we observed a significant increase in the percentage of cells undergoing the late, executive phase of apoptosis in the group of patients with hyperthyroidism compared to euthyroid control subjects (1823.43 \pm 1334.15 vs. $100 \%$ of the control population, respectively; $\mathrm{P}<0.05)$. The results are displayed in Figure 5. However, there were no differences between analyzed groups in percentage of CD34 ${ }^{+}$cells undergoing the early stage of apoptosis $(103.1 \pm 74.16$ vs. $100 \%$ of the control population, respectively).

Concurrently, expression of mRNA for BCL-2 and BCL- $x L$ genes was assessed by real-time RT$\mathrm{PCR}$ in $\mathrm{CD}_{3} 4^{+}$cells isolated from $\mathrm{PB}$ of patients with hyperthyroidism and healthy controls. 


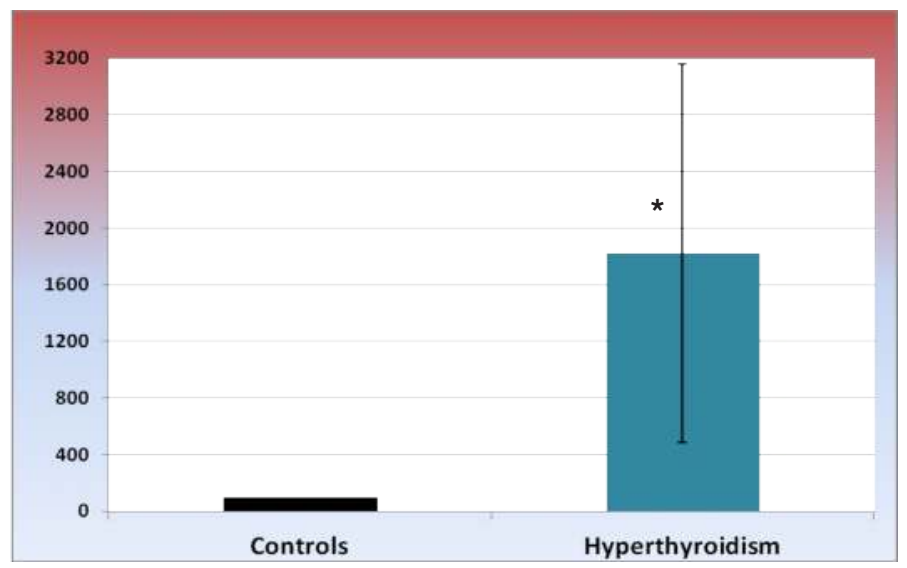

Figure 5. Percentage of human CD34+-enriched hematopoietic stem/progenitor cells in the late apoptotic stage collected from hyperthyroid patients. Apoptosis in hematopoietic progenitor cells collected from patients with hyperthyroidism and healthy subjects (Controls) was scored by cytometric detection of annexin- $\mathrm{V}$ and propidium iodate. Results are expressed as mean percentage $( \pm S D)$ in relation to control values considered as $100 \%$. ${ }^{*} P<0.05$ vs. controls. [21]

We found that both examined anti-apoptotic genes, $B C L-2$ and $B C L-x L$, were significantly down-regulated compared to healthy volunteers ( $40 \%$ and $67 \%$ vs. $100 \%$ respectively; $\mathrm{P}<0.05$ ). In the same manner the expression of $B A X$ gene of pro-apoptotic activity was analyzed. Interestingly, this gene was also significantly down-regulated compared to control subjects ( $36 \%$ vs. $100 \%$ respectively; $\mathrm{P}<0.05$ ). The above data strongly correlate with the previously observed tendency to decrease the clonogenic potential of CD34+hematopoietic stem/progenitor cells of myeloid lineage of hyperthyroid subjects and may indicate that THs at higher concentrations negatively modulate the expression of genes important for hematopoietic cell survival, such as anti-apoptotic BCL-2 and BCL- $x L$ genes. On the other side, the parallel decrease of expression level of pro-apoptotic $B A X$ gene might be related with significant augmentation of late, executive phase of apoptosis in circulating $\mathrm{CD} 34^{+}$cells due to the chronic exposure to elevated concentrations of $\mathrm{T} 3$ found in hyperthyroid patients (Fig. 5). Indeed, $B A X$ is expressed at high levels during the period when programmed cell death is activated by intracellular or extracellular stimuli, and down-regulation of the gene expression occurs thereafter, when signal transduction pathways triggered the performance of apoptotic protein cascade inside the cell [21].

\subsubsection{Thrombocytopoiesis}

Thrombocytopoiesis is the process of thrombocyte generation from the cytoplasm of megakaryocytes located in bone marrow hematopoietic niche. Megakaryocyte maturation comes to completion with the release of thrombocytes, known as platelets, into the bloodstream and each day an adult produces about 100 billion platelets. They are necessary for normal blood clotting. Megakaryocytes normally account for 1 out of 10.000 bone marrow cells but their 
number can increase or decrease in the course of certain diseases, thus resulting in abnormal megakaryocyte function and abnormal platelet quantity or function, and this influences hemostatic system in peripheral blood [85]. In the specialized microenvironment of the bone marrow the megakaryocyte development and subsequent platelets production is regulated through a complex crosstalk between many cell types and cytokines. Especially, thrombopoietin was identified as the major regulator of platelet production, however, other biologically active substances, such as hormones, may play an important role in the regulation of megakaryocyte growth and proliferation [86].

Exactly, one century ago appeared the first report of Kaliebe et al. indicating the clinical relationship between thyroid disease and the dysfunction in hemostatic system. In 1913 the authors have described an episode of central vein thrombosis in a thyrotoxic patient and this medical report was later summarized in 1927 by Doyle, who was studying a possible association between thyrotoxicosis and cerebral vein thrombosis in patients with neurological symptoms [87]. Likewise, various diseases of hemostatic system, ranging from hemostasis disorders, and rarely life-threatening hemorrhages to hypercoagulability and thrombotic events, could be observed in parallel to thyroid gland dysfunctions. However, some contradictory results regarding hemostatic system functions have been obtained in clinical studies of patients with thyroid disorders.

Several published reports have shown a hypercoagulable state in patients with hyperthyroidism $[19,88]$. For certain, patients with hyperthyroidism showed a tendency toward thromboembolic process $(8-40 \%)$, including major emboli at cerebral vasculature, which accounts for nearly $18 \%$ of all deaths associated with thyrotoxicosis [89]. Another systematic analysis also supports an increased risk of venous thrombotic complications, including cerebral venous thrombosis, deep vein thrombosis and pulmonary embolism in patients with hyperthyroidism [90]. Hypercoagulability state that is observed in hyperthyroidism is produced by various coagulation factor (e.g. clotting factors and their inhibitors) abnormalities that occur in patients with hyperthyroidism and are not directly related to thrombocytes and thrombocytopoiesis. Researchers hypothesized that THs may affect the synthesis of many proteins originating from the liver and endothelium by altering the specific gene expression. Indeed, collected data have specified that hyperthyroidism, regardless of its etiology, influences endothelial function by up-regulating the expression levels of vascular adhesion molecules and endothelium-derived proteins important for fibrinolysis, such as tissue-type plasminogen activator and plasminogen activator inhibitor-1 [91]. On the other hand, it is known that there is a general increase of metabolism in hyperthyroid state, which may affect cell components of the peripheral blood and bone marrow. Likewise, it was found that the life-span of platelets is shortened in patients with hyperthyroidism resulting in thrombocytopenia [92]. Moreover, the same group observed that the platelet count increased upon reduction of the concentration of circulating thyroid hormones [92]. Similar data were obtained by Kurata et al., who showed that the platelets count are low and their lifespan shorter in almost one-half of 214 studied patients with Graves' disease [93]. Notwithstanding, thrombocytopenia in patients with hyperthyroidism may have several causes, such as autoimmunity against thromobocytes [94-95] in parallel to nonspecific thyroid antibodies binding to platelets that augment their non-specific 
degradation or due to thrombocyte clearance from plasma by the enhanced phagocytic activity of the reticuloendothelial system [96]. Finally, detected relative low platelet quantities could be due to increased circulating blood volume observed in patients with hyperthyroidism, as in case of other hematologic parameters of blood. Of note, patients with hyperthyroidism had significantly higher risks of having co-morbidities such as hypertension, hyperlipidemia, and diabetes that might affect the survival of platelets and their bone marrow progenitors. Although the pathomechanism is still not well known, altered glucose and lipid metabolism has been often reported in patients with hyperthyroidism [97]. Altogether, the above-mentioned studies have indicated that hyperthyroidism is associated with either increased blood coagulability and endothelial cell dysfunction based on examining the incidence of venous thrombosis, or with thrombocytopenia and decreased life-span of platelets, however, only few scientists attempted to explore the bone marrow-related mechanisms of abnormal functions of hemostatic system among patients with hyperthyroidism. Even the recent development of efficient megakaryocyte cultures in vitro that produce functional platelets has provided the means to study the biology of megakaryopoesis in abnormal pathophysiological conditions, such as hyperthyroid state, the number of reports covering this field is very scanty. In one attempt, to check whether non-physiological THs concentration may directly affect platelet production, it was necessary to determine the quantity of reticulated platelets (RP) circulating in peripheral blood. RP represent young cells recently released from the bone marrow, and according to some reports, their number in peripheral blood reflects thrombopoietic activity [98]. Indeed, Stiegler et al. confirmed that hyperthyroidism was associated with an increased marrow thrombocytopoiesis resulting in elevated RP counts. Moreover this finding was corroborated by observation that RP increase in course of hyperthyroidism was reversible upon achievement of euthyroid state [99]. Furthermore, to confirm the clinical reports indicating that excessive THs exert depressive effects on platelets production, Sullivan et al. used a mouse model to investigate the effects of the hyperthyroid state on thrombocytopoiesis in vivo by administration of T4 into normal healthy mice. They observed that daily thyroxine administration significantly decreased total circulating platelet count and platelet mass due to decreased platelet production. This mechanism was confirmed using the most sensitive methods of assessing platelet production, i.e. percentage of S-35 incorporation into platelets and determination of megakaryocyte size and number [39]. Likewise, Sullivan and coworkers observed that percentage of S-35 incorporation into platelets was reduced and megakaryocyte size and number in bone marrow were considerably decreased [39]. These are only a few available evidences that hyperthyroidism plays a direct role in the fine regulation of thrombocytopoiesis in vivo.

\section{Conclusion}

In recent years there have been published several studies indicating that the thyroid dysfunction could have important implications in human hematopoiesis, and thus might affect various hematological parameters of circulating blood. This chapter demonstrates that hyperthyroid state might be responsible for profound disturbances in functions of the hematopoietic system 
due to the fact that THs modulate hematopoietic cell production in the bone marrow. The hyperthyroidism-related symptoms in peripheral blood comprise increased plasma volume, anemia (10-25\%), leukopenia (10\%), neutropenia, lymphopenia, thrombocytopenia, decreased $\mathrm{MCV}$, and reduced RBC survival, as well as general pancytopenia. Of note, erythrocytosis, lymphocytosis and increased counts of monocytes are also fairly common. Potential molecular mechanisms of reported hematologic symptoms has been explained in part in this paper. Importantly, increased thyroid hormone concentrations influence the mechanisms of the development of hematological abnormalities through both genomic and non-genomic actions. As a result, in patients with different thyroid endocrinopathies, overt hyperthyroidism should be also considered as a possible cause of clinically detectable abnormalities in peripheral blood of these patients. Novel pathophysiological insights into the mechanisms of thyroid hormone actions in the hematopoietic system may help to improve the understanding of the interactions between THs and human hematopoiesis and offer a potential for the future development of novel therapeutic interventions in thyroid diseases.

\section{Author details}

Miłosz P. Kawa* and Bogusław Machaliński

*Address all correspondence to: kawamilosz@gmail.com

Department of General Pathology, Pomeranian Medical University in Szczecin, Szczecin, Poland

\section{References}

[1] Yen PM. Physiological and molecular basis of thyroid hormone action. Physiol Rev. 2001;81(3):1097-142

[2] Murata Y. Multiple isoforms of thyroid hormone receptor: an analysis of their relative contribution in mediating thyroid hormone action. Nagoya J Med Sci. 1998;61(3-4):103-15.

[3] Horwitz KB, Jackson TA, Bain DL, Richer JK, Takimoto GS, Tung L. Nuclear receptor coactivators and corepressors. Mol Endocrinol. 1996;10(10):1167-77.

[4] Lazar MA. Thyroid hormone receptors: Multiple forms, multiple posibilities. Endocr. Rev. 1993;14:184-193.

[5] Wu Y, Koenig RJ. Gene regulation by thyroid hormone. Trends Endocrinol Metab. 2000;11(6):207-11. 
[6] Koenig RJ, Lazar MA, Hodin RA, Brent GA, Larsen PR, Chin WW, Moore DD. Inhibition of thyroid hormone action by a non-hormone binding c-erbA protein generated by alternative mRNA splicing. Nature. 1989;337(6208):659-61.

[7] Davis PJ, Leonard JL, Davis FB. Mechanisms of nongenomic actions of thyroid hormone. Front Neuroendocrinol. 2008;29(2):211-8.

[8] Cheng SY, Leonard JL, Davis PJ. Molecular aspects of thyroid hormone actions. Endocr Rev 2010;31:139-170.

[9] Pascual A, Aranda A. Thyroid hormone receptors, cell growth and differentiation. Biochim Biophys Acta. 2013;1830:3908-16.

[10] Allain TJ, McGregor AM. Thyroid hormones and bone. J Endocrinol. 1993;139(1): 9-18.

[11] Varga F, Rumpler M, Zoehrer R, Turecek C, Spitzer S, Thaler R, Paschalis EP, Klaushofer K. T3 affects expression of collagen I and collagen cross-linking in bone cell cultures. Biochem Biophys Res Commun. 2010;402(2):180-5.

[12] Gorka J, Taylor-Gjevre RM, Arnason T. Metabolic and clinical consequences of hyperthyroidism on bone density. Int J Endocrinol. 2013;2013:638727

[13] Fein HG, Rivlin RS. Anemia in thyroid diseases. Med Clin North Am. 1975;59(5): 1133-45.

[14] Corrocher R, Querena M, Stanzial AM, De Sandre G Microcytosis in hyperthyroidism: haematological profile in thyroid disorders. Haematologica. 1981;66:779-786.

[15] Perlman JA, Sternthal PM. Effect of 131I on the anemia of hyperthyroidism. J Chronic Dis. 1983;36(5):405-12.

[16] Axelrod AR, Bergman L. The bone marrow in hyperthyroidism and hypothyroidism. Blood 1951, 6, 436-453.

[17] Omazic B, Näsman-Björk I, Johansson J, Hentschke P, Mattsson J, Permert J, Lundkvist I. Altered expression of receptors for thyroid hormone and insulin-like growth factor-I during reconstitution after allogeneic hematopoietic stem cell transplantation. Bone Marrow Transplant. 2001;27(11):1163-71.

[18] Squizzato A, Gerdes VE, Brandjes DP, Büller HR, Stam J. Thyroid diseases and cerebrovascular disease. Stroke. 2005;36(10):2302-10.

[19] Squizzato A, Romualdi E, Büller HR, Gerdes VE.J Clinical review: Thyroid dysfunction and effects on coagulation and fibrinolysis: a systematic review. Clin Endocrinol Metab. 2007;92(7):2415-20.

[20] Grymuła K, Paczkowska E, Dziedziejko V, Baśkiewicz-Masiuk M, Kawa M, Baumert B, Celewicz Z, Gawrych E, Machaliński B. The influence of 3,3',5-triiodo-L-thyronine on human haematopoiesis. Cell Prolif. 2007;40(3):302-15. 
[21] Kawa MP, Grymula K, Paczkowska E, Baskiewicz-Masiuk M, Dabkowska E, Koziolek M, Tarnowski M, Kłos P, Dziedziejko V, Kucia M, Syrenicz A, Machalinski B. Clinical relevance of thyroid dysfunction in human haematopoiesis: biochemical and molecular studies. Eur J Endocrinol. 2010;162(2):295-305.

[22] Gruber R, Czerwenka K, Wolf F, Ho GM, Willheim M, Peterlik M Expresion of the vitamin $\mathrm{D}$ receptor, of estrogen and thyroid hormone receptor alfa-and beta-isoforms, and of the androgen receptor in cultures of native mouse bone marrow and stromal/osteoblastic cells. Bone. 1999;24:465-473.

[23] Milne M, Kang MI, Cardona G, Quail JM, Braverman LE, Chin WW, Baran DT Expression of multiple thyroid hormone receptor isoforms in rat femoral and vertebral bone marrow and in bone marrow osteogenic cultures. J. Cell. Biochem. 1999;74:684693.

[24] Davis PJ, Davis FB, Lin HY. Promotion by thyroid hormone of cytoplasm-to-nucleus shuttling of thyroid hormone receptors. Steroids. 2008;73(9-10):1013-7.

[25] Meier-Heusler S, Pernin A, Liang H, Goumaz MO, Burger AG, Meier CA. Quantitation of beta 1 triiodothyronine receptor mRNA in human tissues by competitive reverse transcription polymerase chain reaction. J Endocrinol Invest. 1995;18(10):767-73

[26] Rao JN, Liang JY, Chakraborti P, Feng P. Effect of thyroid hormone on the development and gene expression of hormone receptors in rat testes in vivo. J Endocrinol Invest. 2003;26(5):435-43.

[27] Bauer A, Gandrillon O, Samarut J, Beug H. Nuclear receptors in hematopoietic development: cooperation with growth factor receptors in regulation of proliferation and differentiation. In: Zon L, ed. Hematopoiesis: A Developmental Approach. Oxford, UK: Oxford University Press; 2001; 268-290.

[28] Shalet M, Coe D, Reissmann KR. Mechanism of erythropoietic action of thyroid hormone. Proc Soc Exp Biol Med. 1966;123(2):443-6.

[29] Ford HC, Carter JM. The haematology of hyperthyroidism: abnormalities of erythrocytes, leucocytes, thrombocytes and haemostasis. Postgrad Med J. 1988;64(756): 735-42.

[30] Dainiak N, Sutter D, Kreczko S 1-triiodothyronine augments erythropoietic growth factor release from peripheral blood and bone marrow leukocytes. Blood. 1986;68:1289-1297.

[31] Fandrey J, Pagel H, Frede S, Wolff M, Jelkmann W. Thyroid hormones enhance hypoxia-induced erythropoietin production in vitro. Exp Hematol. 1994;22(3):272-7.

[32] González-Cinca N, Pérez de la Ossa P, Carreras J, Climent F. Effects of thyroid hormone and hypoxia on 2,3-bisphosphoglycerate, bisphosphoglycerate synthase and phosphoglycerate mutase in rabbit erythroblasts and reticulocytes in vivo. Horm Res. 2004;62(4):191-6. 
[33] Tokay A, Raymondjean M, Aliciguzel Y. The effect of thyroid hormones on erythrocyte 2,3-diphosphoglycerate. The Endocrinologist 2006;16:57-60.

[34] Brenner B, Fandrey J, Jelkmann W. Serum immunoreactive erythropoietin in hyperand hypothyroidism: clinical observations related to cell culture studies. Eur J Haematol. 1994;53(1):6-10.

[35] Golde DW, Bersch N, Chopra IJ, Cline MJ. Thyroid hormones stimulate erythropoiesis in vitro. Br. J. Haematol. 1977;37:173-177.

[36] Schroeder C, Gibson L, Zenke M, Beug H. Modulation of normal erythroid differentiation by the endogenous thyroid hormone and retinoic acid receptors: a possible target for v-erbA oncogene action. Oncogene 1992;7:217-227.

[37] Malgor LA, Valsecia ME, Verges EG, de Markowsky EE. Enhancement of erythroid colony growth by triiodothyronine in cell cultures from bone marrow of normal and anemic rats with chronic renal failure. Acta Physiol Pharmacol Ther Latinoam. 1995;45(2):79-86.

[38] Perrin MC, Blanchet JP, Mouchiroud G. Modulation of human and mouse erythropoiesis by thyroid hormone and retinoic acid: evidence for specific effects at different steps of the erythroid pathway. Hematol. Cell Ther. 1997;39:19-26.

[39] Sullivan PS, McDonald TP. Thyroxine suppresses thrombocytopoiesis and stimulates erythropoiesis in mice. Proc Soc Exp Biol Med. 1992;201(3):271-7.

[40] Bauer A, Mikulits W, Lagger G, Stengl G, Brosch G, Beug H. The thyroid hormone receptor functions as a ligand-operated developmental switch between proliferation and differentiation of erythroid progenitors. EMBO J. 1998;17(15):4291-303.

[41] Kendrick TS, Payne CJ, Epis MR, Schneider JR, Leedman PJ, Klinken SP, Ingley E. Erythroid defects in TRalpha-/-mice. Blood. 2008;111(6):3245-8.

[42] Leberbauer C, Boulmé F, Unfried G, Huber J, Beug H, Müllner EW. Different steroids co-regulate long-term expansion versus terminal differentiation in primary human erythroid progenitors. Blood. 2005;105(1):85-94.

[43] Gianoukakis AG, Leigh MJ, Richards P, Christenson PD, Hakimian A, Fu P, Niihara $\mathrm{Y}$, Smith TJ. Characterization of the anaemia associated with Graves' disease. Clin Endocrinol (Oxf). 2009;70(5):781-7.

[44] Nightingale S, Vitek PJ, Himsworth RL. The haematology of hyperthyroidism. Q J Med. 1978;47(185):35-47.

[45] Muldowney FP, Crooks J, Wayne EJ. The total red cell mass in thyrotoxicosis and myxoedema. Clin Sci (Lond). 1957;16(2):309-14.

[46] Boelaert K, Newby PR, Simmonds MJ, Holder RL, Carr-Smith JD, Heward JM, Manji N, Allahabadia A, Armitage M, Chatterjee KV, Lazarus JH, Pearce SH, Vaidya B, 
Gough SC, Franklyn JA. Prevalence and relative risk of other autoimmune diseases in subjects with autoimmune thyroid disease. Am J Med. 2010;123(2):183.e1-9.

[47] McClellan JE, Donegan C., Thorup OA, Leavell BS. Survival time of the erythrocyte in myxedema and hyperthyroidism. J Lab Clin Med. 1958;51(1):91-6.

[48] Donati RM, Warnecke MA, Gallagher NI. Ferrokinetics in hyperthyroidism. Ann Intern Med. 1965;63(6):945-50.

[49] Duquenne M, Lakomsky D, Humbert JC, Hadjadj S, Weryha G, Leclère J. Pancytopenia resolved by the treatment of hyperthyroidism. Presse Med. 1995;24(17):807-10.

[50] Shaw B, Mehta AB. Pancytopenia responding to treatment of hyperthyroidism: a clinical case and review of the literature. Clin Lab Haematol. 2002;24(6):385-7.

[51] Lima CS, Zantut Wittmann DE, Castro V, Tambascia MA, Lorand-Metze I, Saad ST, Costa FF. Pancytopenia in untreated patients with Graves' disease. Thyroid. 2006;16(4):403-9.

[52] Haddad JJ, Saadé NE, Safieh-Garabedian B. Cytokines and neuro-immune-endocrine interactions: a role for the hypothalamic-pituitary-adrenal revolving axis. J Neuroimmunol. 2002;133(1-2):1-19.

[53] Pállinger E, Csaba G.; A hormone map of human immune cells showing the presence of adrenocorticotropic hormone, triiodothyronine and endorphin in immunophenotyped white blood cells. Immunology. 2008;123(4):584-9.

[54] Csaba G, Pállinger E. Thyrotropic hormone (TSH) regulation of triiodothyronine (T(3)) concentration in immune cells. Inflamm Res. 2009;58(3):151-4.

[55] Balázs C, Leövey A, Szabó M, Bakó G. Stimulating effect of triiodothyronine on cellmediated immunity. Eur J Clin Pharmacol. 1980;17(1):19-23.

[56] Ong ML, Malkin DG, Malkin A. Alteration of lymphocyte reactivities by thyroid hormones. Int J Immunopharmacol. 1986;8(7):755-62.

[57] Barreiro Arcos ML, Sterle HA, Paulazo MA, Valli E, Klecha AJ, Isse B, Pellizas CG, Farias RN, Cremaschi GA. Cooperative nongenomic and genomic actions on thyroid hormone mediated-modulation of $\mathrm{T}$ cell proliferation involve up-regulation of thyroid hormone receptor and inducible nitric oxide synthase expression. J Cell Physiol. 2011;226(12):3208-18.

[58] Hodkinson CF, Simpson EE, Beattie JH, O'Connor JM, Campbell DJ, Strain JJ, Wallace JM. Preliminary evidence of immune function modulation by thyroid hormones in healthy men and women aged 55-70 years. J Endocrinol. 2009;202(1):55-63.

[59] Dorshkind K, Horseman ND. The roles of prolactin, growth hormone, insulin-like growth factor-I, and thyroid hormones in lymphocyte development and function: insights from genetic models of hormone and hormone receptor deficiency. Endocr Rev. 2000;21(3):292-312. 
[60] Bloehr H, Bregengaard C, Povlsen JV. Triiodothyronine stimulates growth of peripheral blood mononuclear cells in serum-free cultures in uremic patients. Am J Nephrol. 1992;12(3):148-54.

[61] El-Shaikh KA, Gabry MS, Othman GA. Recovery of age-dependent immunological deterioration in old mice by thyroxine treatment. J Anim Physiol Anim Nutr (Berl). 2006;90(5-6):244-54.

[62] De Vito P, Incerpi S, Pedersen JZ, Luly P, Davis FB, Davis PJ. Thyroid hormones as modulators of immune activities at the cellular level. Thyroid. 2011;21(8):879-90.

[63] Pacini F, Nakamura H, DeGroot LJ. Effect of hypo-and hyperthyroidism on the balance between helper and suppressor $\mathrm{T}$ cells in rats. Acta Endocrinol (Copenh). 1983;103(4):528-34.

[64] Christ-Crain M, Meier C, Huber P, Zulewski H, Staub JJ, Müller B. Effect of restoration of euthyroidism on peripheral blood cells and erythropoietin in women with subclinical hypothyroidism. Hormones (Athens). 2003;2(4):237-42.

[65] Porter L, Mandel SJ. The Blood in Thyrotoxicosis. In: Brawerman LE, Utiger RD, eds. Werner \& Ingbar's The Thyroid, Philadelphia: Lippincott Williams, Wilkins; 2000; 627-630.

[66] Garcia-Suarez J, Prieto A, Reyes E, Arribalzaga K, Perez-Machado MA, Lopez-Rubio M, Manzano L, Alvarez-Mon M. Persistent lymphocytosis of natural killer cells in autoimmune thrombocytopenic purpura (ATP) patients after splenectomy. Br J Haematol. 1995;89(3):653-5.

[67] Grossi A, Nozzoli C, Gheri R, Santini V, Marrani C, Zoccolante A, Ferrini PR. Pure red cell aplasia in autoimmune polyglandular syndrome with $\mathrm{T}$ lymphocytosis. Haematologica. 1998;83(11):1043-5.

[68] Notario A, Torriani A, Bravi M, Broglia M, Borghi G, Guerra G. The influence of thyroid hormones on colony growth of peripheral CFU-GM from normal and leukemic subjects. Tumori. 1988;74(5):507-12.

[69] Notario A, Mazzucchelli I, Fossati L, Baldi A, Rolandi ML. Qalqili A. International Journal of Immunopathology and Pharmacology 1997;10:133-138.

[70] Ponassi A, Morra L, Caristo G, Parodi GB, Biassoni P, Sacchetti C. Disorders of granulopoiesis in patients with untreated Graves' disease. Acta Haematol. 1983;70(1): 19-23.

[71] Kucharova S, Farkas R. Hormone nuclear receptors and their ligands: role in programmed cell death (review). Endocr Regul. 2002;36(1):37-60.

[72] Alisi A, Demori I, Spagnuolo S, Pierantozzi E, Fugassa E, Leoni S. Thyroid status affects rat liver regeneration after partial hepatectomy by regulating cell cycle and apoptosis. Cell Physiol Biochem. 2005;15(1-4):69-76. 
[73] Yehuda-Shnaidman E, Kalderon B, Bar-Tana J. Modulation of mitochondrial transition pore components by thyroid hormone. Endocrinology. 2005;146(5):2462-72.

[74] Chiloeches A, Sánchez-Pacheco A, Gil-Araujo B, Aranda A, Lasa M. Thyroid hormone-mediated activation of the ERK/dual specificity phosphatase 1 pathway augments the apoptosis of GH4C1 cells by down-regulating nuclear factor-kappaB activity. Mol Endocrinol. 2008;22(11):2466-80.

[75] Wang YY, Jiao B, Guo WG, Che HL, Yu ZB. Excessive thyroxine enhances susceptibility to apoptosis and decreases contractility of cardiomyocytes. Mol Cell Endocrinol. 2010;320(1-2):67-75.

[76] Sar P, Peter R, Rath B, Das Mohapatra A, Mishra SK. 3, 3'5 Triiodo L thyronine induces apoptosis in human breast cancer MCF-7 cells, repressing SMP30 expression through negative thyroid response elements. PLoS One. 2011;6(6):e20861.

[77] Yamada-Okabe T, Satoh Y, Yamada-Okabe H. Thyroid hormone induces the expression of $4-1 \mathrm{BB}$ and activation of caspases in a thyroid hormone receptor-dependent manner. Eur J Biochem. 2003;270(14):3064-73

[78] Zhang L, Cooper-Kuhn CM, Nannmark U, Blomgren K, Kuhn HG. Stimulatory effects of thyroid hormone on brain angiogenesis in vivo and in vitro. J Cereb Blood Flow Metab. 2010;30(2):323-35.

[79] Lin HY, Tang HY, Keating T, Wu YH, Shih A, Hammond D, Sun M, Hercbergs A, Davis FB, Davis PJ. Resveratrol is pro-apoptotic and thyroid hormone is anti-apoptotic in glioma cells: both actions are integrin and ERK mediated. Carcinogenesis. 2008;29(1):62-9.

[80] Barreiro Arcos ML, Gorelik G, Klecha A, Genaro AM, Cremaschi GA. Thyroid hormones increase inducible nitric oxide synthase gene expression downstream from PKC-zeta in murine tumor $\mathrm{T}$ lymphocytes. Am J Physiol Cell Physiol. 2006;291(2):C327-36.

[81] Medh RD, Thompson EB. Hormonal regulation of physiological cell turnover and apoptosis. Cell Tissue Res. 2000;301(1):101-24.

[82] Mihara S, Suzuki N, Wakisaka S, Suzuki S, Sekita N, Yamamoto S, Saito N, Hoshino T, Sakane T. Effects of thyroid hormones on apoptotic cell death of human lymphocytes. J Clin Endocrinol Metab. 1999;84(4):1378-85.

[83] Gandrillon O, Ferrand N, Michaille JJ, Roze L, Zile MH, Samarut J. C-erbA alpha/T3R and RARs control commitment of hematopoietic self-renewing progenitor cells to apoptosis or differentiation and are antagonized by the v-erbA oncogene. Oncogene 1994;9,749-758

[84] Hara M, Suzuki S, Mori J, Yamashita K, Kumagai M, Sakuma T, Kakizawa T, Takeda T, Miyamoto T, Ichikawa K, Hashizume K. Thyroid hormone regulation of apoptosis induced by retinoic acid in promyeloluekemic HL-60 cells: studies with retinoic acid 
receptor-specific and retinoid X receptor-specific ligands. Thyroid 2000;10,10231034.

[85] Branehög I, Ridell B, Swolin B, Weinfeld A. Megakaryocyte quantifications in relation to thrombokinetics in primary thrombocythaemia and allied diseases. Scand J Haematol. 1975;15(5):321-32.

[86] Kaushansky K. Historical review: megakaryopoiesis and thrombopoiesis. Blood. 2008;111(3):981-6.

[87] Doyle JB. Obstruction of the longitudinal sinus. Arch Neurol Psychiatry. 1927;29,374382.

[88] Marongiu F, Cauli C, Mariotti S. Thyroid, hemostasis and thrombosis. J Endocrinol Invest. 2004;27(11):1065-71.

[89] Hofbauer LC, Heufelder AE. Coagulation disorders in thyroid diseases. Eur J Endocrinol. 1997;136(1):1-7.

[90] Franchini M, Lippi G, Targher G. Hyperthyroidism and venous thrombosis: a casual or causal association? A systematic literature review. Clin Appl Thromb Hemost. 2011;17(4):387-92.

[91] Burggraaf J, Lalezari S, Emeis JJ, Vischer UM, de Meyer PH, Pijl H, Cohen AF. Endothelial function in patients with hyperthyroidism before and after treatment with propranolol and thiamazol. Thyroid. 2001;11(2):153-60.

[92] Panzer S, Haubenstock A, Minar E. Platelets in hyperthyroidism: studies on platelet counts, mean platelet volume, 111-indium-labeled platelet kinetics, and platelet-associated immunoglobulins G and M. J Clin Endocrinol Metab. 1990;70(2):491-6.

[93] Kurata Y, Nishioeda Y, Tsubakio T, Kitani T. Thrombocytopenia in Graves' disease: effect of T3 on platelet kinetics. Acta Haematol. 1980;63(4):185-90.

[94] Bizzaro N. Familial association of autoimmune thrombocytopenia and hyperthyroidism. Am J Hematol. 1992;39(4):294-8

[95] Cordiano I, Betterle C, Spadaccino CA, Soini B, Girolami A, Fabris F. Autoimmune thrombocytopenia (AITP) and thyroid autoimmune disease (TAD): overlapping syndromes? Clin Exp Immunol. 1998;113(3):373-8.

[96] Adrouny A, Sandler RM, Carmel R. Variable presentation of thrombocytopenia in Graves' disease. Arch Intern Med. 1982;142(8):1460-4.

[97] Dimitriadis G, Mitrou P, Lambadiari V, Boutati E, Maratou E, Koukkou E, Tzanela M, Thalassinos N, Raptis SA. J Clin Endocrinol Metab. Glucose and lipid fluxes in the adipose tissue after meal ingestion in hyperthyroidism. 2006;91(3):1112-8.

[98] Ault KA, Knowles C. In vivo biotinylation demonstrates that reticulated platelets are the youngest platelets in circulation. Exp Hematol. 1995;23(9):996-1001. 
[99] Stiegler G, Stohlawetz P, Brugger S, Jilma B, Vierhapper H, Höcker P, Panzer S. Elevated numbers of reticulated platelets in hyperthyroidism: direct evidence for an increase of thrombopoiesis. Br J Haematol. 1998 Jun;101(4):656-8. 